\title{
Entre o real e o ficcional: uma análise do romance $A$ Casa Verde (1898-1899)
}

\author{
Between the real and the fictional: an analysis of the novel $A$ Casa \\ Verde (1898-1899)
}

Deivid Aparecido Costruba*

Resumo: O presente artigo tem como objetivo discutir os limites entre o real e o ficcional no romance $A$ Casa Verde, escrito pelo casal Filinto de Almeida (1857-1945) e Julia Lopes de Almeida (1862-1934), publicado em folhetim no Jornal do Comercio, entre 1898 e 1899 . O título da obra foi motivado pelo da residência dos cônjuges, situada no bairro de Santa Tereza, no Rio de Janeiro, conhecida pela intelectualidade da época como o "Salão Verde". $\mathrm{Na}$ escrita do romance foram abordados alguns temas caros aos escritores, que procuram não só examinar a imagem da mulher na sociedade daquele momento, como também o de estruturar o texto em torno de aspectos da anglofilia.

Palavras-chave: Filinto de Almeida; Julia Lopes de Almeida; literatura; romance; A Casa Verde.

\begin{abstract}
The present article aims to discuss the boundaries between the real and the fictional in the novel $A$ Casa Verde, written by the couple Filinto de Almeida (1857-1945) and Julia Lopes de Almeida (1862-1934) and published in a book in the Jornal do Comércio, between 1898 and 1899. The title of the work in question has a name similar to the residence of the spouses, located in the district of Santa Tereza, in Rio de Janeiro, known by the time of the time as "Salão Verde". In the writing of the novel were addressed some expensive themes for writers who seek not only to examine an image of women in society at the time, as well as to structure the text around Anglophilia.
\end{abstract}

Keywords: Filinto de Almeida; Julia Lopes de Almeida; literature; novel; $A$ Casa Verde.

* Doutorando em História e Sociedade pela Faculdade de Ciências e Letras, UNESP - Universidade Estadual Paulista, Assis/SP, Brasil. E-mail: costrubahistunesp@hotmail.com

(c) EY Direito autoral e licença de uso: Este artigo está licenciado sob uma Licença Creative Commons. Com essa licença você pode compartilhar, adaptar, para qualquer fim, desde que atribua a autoria da obra, forneça um link para a licença, e indicar se foram feitas alterações. 


\section{Introdução}

Este artigo tem como mote problematizar o romance $A$ Casa Verde, escrito pelo casal Filinto de Almeida e Julia Lopes de Almeida. A obra foi primeiramente publicada em folhetins no Rio de Janeiro pelo Jornal do Comercio, entre 18 de dezembro de 1898 e 16 de março de 1899. Trinta e três anos mais tarde, o volume também foi publicado em livro pela Companhia Editora Nacional, fundada por Monteiro Lobato, em 1925. O título da obra faz clara referência à residência dos cônjuges localizada no bairro de Santa Tereza, no Rio de Janeiro. O famoso "Salão Verde" era, nas palavras de João Luso, escritor luso-brasileiro e amigo do casal, um ambiente ao mesmo tempo patriarcal e de culto às artes.

Antes de se avançar na análise, é preciso trazer as reflexões teóricometodológicas de autores que discutiram a fonte literária e seus suportes, cujos ensinamentos servirão de balizas para esta investigação. No que diz respeito aos documentos literários, de acordo com Antonio Celso Ferreira, o historiador deve-se pautar pela "interpretação das fontes em determinadas circunstâncias sociais, isto é, nos contextos, que só podem ser reconstruídos, ainda que de modo parcial, lacunar e aproximado, pela mediação de outros textos". ${ }^{1}$ Dessa forma, no decorrer da presente análise, serão empregados outros textos para reconstruir o universo sócio intelectual da conhecida residência dos Almeida. Também no exame aqui proposto, as considerações de Ferreira serão ponderadas, tendo em conta algumas das problemáticas no uso da fonte literária, processo habitual em uma investigação histórica.

Pode-se partir de perguntas elementares tais como: quem eram os escritores selecionados para a pesquisa... Em que realidade social ou econômica, política e cultural eles viviam, como e por que se lançaram à criação ficcional?... Que significados atribuíram à literatura e que significados históricos podem ser lidos em suas obras? Que representação do mundo social eles criaram? Que desejos, angústias, utopias ou frustações expressaram e o que isso tinha a ver com a vida coletiva da época? ${ }^{2}$

Se a trajetória do "salão verde" foi artisticamente agitada, servindo até mesmo, segundo Michele Fanini, como a "antessala" da Academia Brasileira de Letras, o pano de fundo da obra $A$ Casa Verde confundia-se, muitas vezes, com o cenário real do Rio de Janeiro. Ao descrever a atividade de um guardalivros $^{3}$, os autores afirmaram:

Comprazia-se no movimento de grandes volumes, as pesadas pipas de vinho, os fardos de fazendas grossas, os caixões de ferragens, os gigos de louça, as sacas de café, 
as malas de carne seca, as barricas de farinha, as tinas de bacalhau, os rolos de papel impressão, os surrões de mate, os barris de manteiga e banha, as latas de óleos, os molhos de barras de ferro... e ia às vezes para os vastos armazéns da Alfândega, só para ver as avalanches desses volumes rolarem de cima para baixo e de baixo para cima, nos carros dos trilhos, nos ascensores, nos possantes guindastes de ferro movidos a vapor, rangendo nas engrenagens formidandas, agitando no ar, com fragor, grossas correntes passadas e repassada nos motões, suspendendo dúzias de caixas ou de fardos enlaçados por estopo grossos ou engatados por unhas de ferro. ${ }^{4}$

Esse relato, vivenciado pelos autores e articulados à imaginação literária do casal, explicita muito bem o que Nicolau Sevcenko considera sobre a liberdade de criação do escritor:

[...] todo escritor possui uma espécie de liberdade condicional de criação, uma vez que seus temas, motivos, valores, normas ou revoltas são fornecidos ou sugeridos pela sua sociedade de seu tempo - e é destes que eles falam. Fora de qualquer dúvida: a literatura é antes de mais nada um produto artístico, destinado a agradar e comover; mas como se pode imaginar uma árvore sem raízes, ou como pode a qualidade dos seus frutos não depender das características do solo, da natureza, do clima e das condições ambientais?

No que diz respeito à análise interna do romance, é importante observar, de acordo com Tania Regina de Luca, a dimensão do objeto investigado. Em outras palavras, o documento deve ser analisado, sobretudo quanto às "condições técnicas de produção vigentes e a averiguação, dentro de tudo que se dispunha, do que foi escolhido e por quê". ${ }^{6}$

De posse dessas orientações teórico-metodológicas, cabe, a partir daqui, traçar um perfil biográfico para se entender o contexto cultural e familiar do casal. Os autores de $A$ Casa Verde conheceram-se em 1885, quando Julia Lopes tornou-se colaboradora da revista $A$ Semana, cuja editoria chefe era conferida a Filinto de Almeida.

Francisco Filinto de Almeida (1857-1945) nasceu na cidade do Porto, no dia 4 de dezembro de 1857, e entrou para o Colégio Primário, mas não chegou a concluir os estudos. Aos dez anos de idade, desembarcou na cidade do Rio Grande (RS), em 15 de janeiro de 1868, acompanhado de parentes maternos, que eram capitães de navios. Em terras brasileiras, primeiramente trabalhou como empregado em uma papelaria. $\mathrm{O}$ ainda desconhecido escritor não cursou qualquer estabelecimento de ensino. Foi pelo seu esforço e autodidatismo 
que se destacou no jornalismo e nas letras, ao estrear como escritor aos 19 anos, com o entreato cômico Um idioma, representado no Teatro Vaudeville, em 16 de julho de 1876. No ano de 1887, publicou Os mosquitos, monólogo cômico em versos, e Lírica. Uma vez inserido nesse meio literário, fundou com Valentim de Magalhães o jornal A Semana, no qual escreveu, de 1886 a 1887, crônicas hebdomadárias, com o pseudônimo de "Filindal". Após a Proclamação da República, foi considerado brasileiro, pois não declarou "o ânimo de conservar a nacionalidade de origem", conforme propunha a nova Constituição promulgada. ${ }^{7}$ Em seguida, a convite de $O$ Estado de S. Paulo, foi redator do matutino entre 1889 e 1895 . Trabalhou ainda como deputado da Assembleia Legislativa de S. Paulo, de 1892 a 1897. Também se notabilizou como um dos fundadores da Academia Brasileira de Letras, ocupando a cadeira de $\mathrm{n}^{\mathrm{0}} 3$, cujo patrono foi Artur de Oliveira, de quem fora amigo. ${ }^{8}$

Já a escritora Júlia Valentina da Silveira Lopes (1862-1934) nasceu no casarão da Rua do Lavradio, $n^{\circ}$ 53, na cidade Rio de Janeiro. Ainda na infância, transferiu-se com a família para Campinas, interior de São Paulo e iniciou seu trabalho na imprensa aos 19 anos, ao publicar, em A Gazeta de Campinas, uma apreciação sobre o desempenho da atriz italiana Gemma Cunibert. O artigo foi feito a pedido de seu pai, Valentim José da Silveira Lopes (1830-1915), médico e diletante das letras, que, para convencer a filha afirmou estar impossibilitado de fazê-lo. ${ }^{9}$ A partir de então, Júlia Lopes passou a colaborar nesse jornal e em outros periódicos, indicada por Carlos Ferreira ${ }^{10}$, redator e posteriormente diretor de $A$ Gazeta de Campinas, que lhe escreveu pedindo a resenha da nova edição de um livro de Casemiro de Abreu.

Três anos depois, em 1884, a escritora começou a escrever também para O País, colaboração que durou mais de três décadas. Mas foi em Lisboa, para onde se mudou em 1886, que se lançou definitivamente como escritora, ao publicar a obra Contos Infantis, em parceria com sua irmã Adelina Vieira. Foi em terras portuguesas também que o enlace matrimonial com o jovem Filinto finalmente aconteceu, após quase dois anos de namoro, em 28 de novembro de 1887. Segundo relatos do neto da escritora ${ }^{11}$, o pai de Júlia Lopes, desconfiado das reais intenções de seu pretendente, deixou claro que o casamento só aconteceria caso Filinto se dispusesse a ir até Portugal e lá se casasse. Tal ato seria considerado pela família uma prova real de seu sentimento pela escritora. Após a cerimônia, Julia, que até então assinava apenas Lopes, incorporou o sobrenome do marido e tornou-se Julia Lopes de Almeida.

De volta ao Brasil, em 1888, publicou seu primeiro romance, Memórias de Marta, que veio a público inicialmente em folhetins veiculados pelo $O$ País. Sua atividade em jornais e revistas, como no Jornal do Commercio, A Semana, Ilustração Brasileira, Tribuna Liberal, entre outros, foi incessante e, na maior parte das vezes, tocava em temas candentes, sendo, por exemplo, explicitamente a favor da abolição e da República, em artigos que tratavam 
da questão. A escritora foi uma das primeiras romancistas brasileiras, e sua produção literária foi prolífica, abrangendo vários gêneros, como contos, peças teatrais, crônicas e literatura infantil. Seu estilo foi marcado pela influência do realismo e do naturalismo francês, especialmente aquele pertencente à obra de Guy de Maupassant (1850 - 1893) e Émile Zola (1840 - 1902), dos quais era uma profunda admiradora. ${ }^{12}$

A cidade do Rio de Janeiro, então capital federal, foi o cenário de suas ficções, assim como o ambiente privado das famílias burguesas serviu às tramas e à construção de seus personagens, como exemplificado no romance $A$ Falência, lançado em 1901, que, para muitos, teria sido sua obra mais importante. Júlia ainda obteve destaque no Brasil e no exterior em conferências e palestras sobre temas nacionais e relacionados à mulher brasileira. Sua intensa participação em sociedades femininas no Rio de Janeiro envolvia uma série de pautas que incluíam, sobretudo, o direito feminino ao voto. Juntamente com seu esposo, esteve presente nos debates para a criação de uma sociedade de letras no Rio de Janeiro, que se consolidaria na fundação da futura Academia Brasileira de Letras, em 1897.

Apesar de Julia Lopes pertencer ao círculo intelectual que planejou a instituição, não pôde figurar entre seus membros. A não admissão da escritora na Academia deveu-se à fiel observância, por parte dos intelectuais brasileiros, dos critérios de admissão adotados pela Académie Française de Lettres, que previa apenas o ingresso de acadêmicos do sexo masculino. Uma vez que não lhe foi permitido integrar o rol, seu marido, Filinto de Almeida, foi incluído na vaga que, supostamente, pertenceria a Julia Lopes. Por essa razão, algumas notas a respeito da formação da Academia foram escritas na imprensa, como esta presente no jornal O Estado de S. Paulo, na seção "Jornais do Rio":

Noticia a fundação de uma Academia de Letras. A iniciativa foi do sr. Lúcio de Mendonça, que aproveitou a circunstância de se achar na direção do ministério do interior o sr. A. Torres, um homem de letras. A Academia será criada provavelmente, por decreto de 15 de novembro deste ano. Na mesma data o governo nomeará os primeiros dez acadêmicos e estes elegerão outros vinte e mais dez correspondentes, dentro os escritores nacionais residentes no Estado ou no estrangeiro. ${ }^{13}$

O intuito de Lúcio de Mendonça, o "infatigável promotor da mulher no mundo das letras" ${ }^{14}$, era viabilizar o nome de Júlia Lopes. Para isso, Mendonça escreveu vários artigos intitulados "Cartas Literárias", que considerava os quarenta nomes que pareceriam dignos de notabilizarem-se como fundadores da instituição; entre eles, vinte e quatro se tornaram fundadores e três deles ingressaram posteriormente. ${ }^{15}$ 
E entre esses nomes estava o de uma grande escritora, conhecida como a maior de seu tempo, Júlia Lopes de Almeida, que sobrepujaria não só ao marido, Filinto de Almeida, como também a José do Patrocínio, Sílvio Romero, Domicílio da Gama, Eduardo Prado, Clóvis Beviláqua, Raimundo Correia e Oliveira Lima. ${ }^{16}$

Contudo, os esforços do literato foram em vão, visto que grande parte dos homens de letras não aceitou qualquer presença feminina na instituição. A despeito da não concordância em relação ao nome de Júlia Lopes, Mendonça publicou outro texto intitulado "As três Júlias"17, no qual relatou seu sentimento de frustração:

Na fundação da Academia Brasileira de Letras, era a ideia de alguns de nós, como Valentim de Magalhães e Filinto de Almeida, admitirmos a gente de outro sexo; mas a ideia caiu, foi vivamente combatida por outros, irredutíveis inimigos das machonas, segundo a brutal denominação de um ilustre confrade, cujo desembaraço rendeu os dissabores que conhecem. Com tal exclusão, ficamos inibidos de oferecer a espíritos tão finamente literários como o das três Julias o cenário em que poderiam brilhar a toda luz. ${ }^{18}$

O escritor maranhense Humberto de Campos, ao comentar o imbróglio, afirmava sobre Júlia Lopes: "ela própria, pela nacionalidade, pelo talento, mais acadêmico que o marido" merecia o posto ${ }^{19}$. Assim, como já havia afirmado Michele Fanini, o impedimento de Julia Lopes na ABL só atesta a ideia que os homens de letras, fundadores da instituição, estavam alicerçados no princípio de que a feminilidade era um "fator" de inegável subtração do capital simbólico. Segundo Pierre Bourdieu:

Também sempre vi na dominação masculina, e no modo que é imposta e vivenciada, o exemplo por excelência desta submissão paradoxal, resultante daquilo que eu chamo de violência simbólica, violência suave, insensível, invisível às suas próprias vítimas, que se exerce essencialmente pelas vias puramente simbólicas da comunicação e do conhecimento, ou, mais precisamente, do desconhecimento ou, em última instância, do sentimento. ${ }^{20}$

Por sua vez, a situação de Filinto de Almeida era delicada no que diz respeito à sua nacionalidade. Segundo o Regimento Interno recém-formulado pelos fundadores iniciais da Academia Brasileira de Letras, o ingresso à ABL se limitava apenas aos brasileiros. Desse modo, por ser português nato, 
teoricamente, estaria automaticamente descartada sua inclusão. No entanto, o escritor foi agraciado pela "naturalização tácita", ao se favorecer da chamada "lei da grande naturalização", que permitia aos estrangeiros residentes no país manifestar o desejo de não manter sua nacionalidade portuguesa. ${ }^{21}$

\section{O "Salão Verde" dos Almeida, sua rede de relações e as tertúlias literárias}

As relações estabelecidas pelo casal, muitas vezes a partir do contato com outros escritores nas redações dos jornais e em diversas ocasiões, fizeram que recebesse em sua residência, em Santa Tereza, a maior parte da intelectualidade da época. Não seria exagero afirmar que a moradia foi ponto de encontro dos homens de letras do Rio de Janeiro, que contou com a presença de intelectuais brasileiros e estrangeiros, como Valentim de Magalhães, Araripe Jr., Olavo Bilac, Lúcio de Mendonça, João Luso, Francisco Alves, João do Rio, Antonio Parreira, Amoedo, Albero Nepomuceno, Júlia Cortines, Maria Clara da Cunha Santos e ainda atores, pintores e jornalistas.

\section{Figura 1 - Fachada da residência do casal Julia e Filinto, localizada no bairro de Santa Tereza (RJ) [s.d.]}

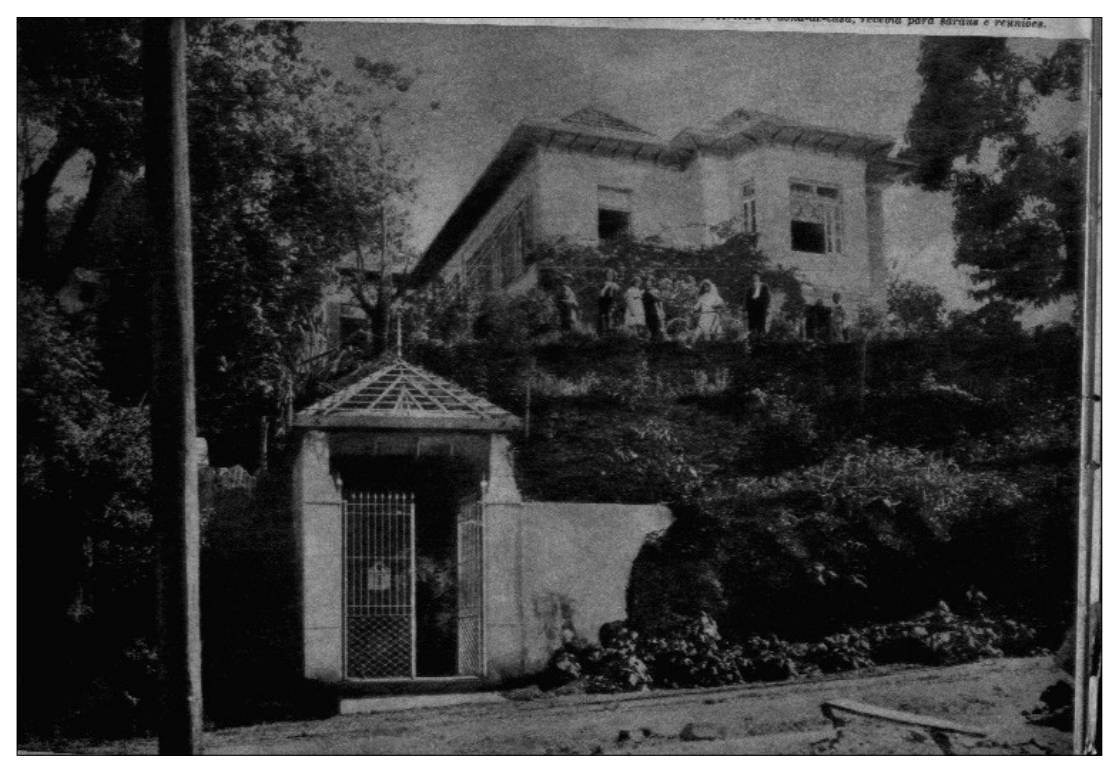

Fonte: Acervo Claudio Lopes de Almeida

Reunir-se na residência do casal se tornou um evento social para os intelectuais daquele momento. Como se pode observar na figura, o domicílio dos Almeida era rodeado de vegetação, o que lhe rendeu a alcunha de "salão verde". Constantemente, a imprensa divulgava os encontros que seriam 
realizados na casa. O jornal O Imparcial noticiou, em 1917, que a "eminente escritora sra. Júlia Lopes de Almeida está preparando uma festa magnífica de arte e caridade, a realizar-se nos jardins de sua encantadora vivenda, em Santa Tereza". Não se tratava de uma mera reunião, pois, conforme informava o impresso, se organizariam atrações para entreter os convidados: "[...] Quanto ao programa, sabemos que será representado o ato bíblico "Nos jardins de Saul" da lavra da brilhante escritora". ${ }^{22}$ Uma semana após o anúncio, a tertúlia foi oficialmente definida:

\begin{abstract}
A primeira parte constará da representação do ato bíblico da sra. Júlia Lopes de Almeida, "Nos Jardins de Saul", com música do maestro Nepomuceno. Tomarão parte na representação: sra. Margarida Lopes de Almeida, "Merob", filha de Saul; sra. Adelaide Lopes Gonçalves, "Marta", serva de "Merob"; sra. Lúcia Lopes de Almeida, "Zagala"; srta. Hermínia R. da Cunha, "Abigail", serva; sra. Sarah Cabral, "Thamar", serva; srta. Nadine Tross, "Sarvia", serva; srta. Consuelo Gabell, "Jesrael", serva; srta. Ivy de Castro, "Esther", serva; sra. Afonso Lopes de Almeida, "Sarah", serva; sr. Albano Lopes de Almeida, "David"; sr. Nestor Figueiredo, "Siba"; sr. Oswaldo Menezes, "Guarda". Servirá de ponto o dr. A. Moraes Coutinho Filho. A segunda parte constará de canções, pela sra. Bebê Lima Castro, ária de "Fígaro", do "Barbeiro de Sevilha", pelo sr. Nascimento Filho; "O poeta e a sombra", de Afonso Lopes de Almeida, pelo autor, e srta. Margarida Lopes de Almeida; dueto de violão, pelos srs. Castro Afilhado e Brant Horta; cena cómica, pelo sr. J. Armstrong Reed; canção e dança espanhola, senhorita Conzuello Gatall: "A mentira do luar", serenata de Filinto de Almeida; música de X, senhoritas Elena Van Erven, Margarida Lopes de Almeida e sr. Pedro Bruno. ${ }^{23}$
\end{abstract}

Nota-se no excerto a presença volumosa da família Lopes de Almeida, que contaria não só com os filhos do casal, mas também com parentes próximos que encenariam a peça e interpretariam canções. A reunião ocorreria no dia 05 de janeiro de 1918 e foi amplamente divulgada dias antes do evento, na seção Notas Sociais. Os encontros prosseguiram na década de 1920 e novamente O Imparcial, em 06 de junho de 1921, divulgou que, na "residência do ilustre acadêmico Filinto de Almeida e D. Júlia Lopes de Almeida, realizouse anteontem uma recepção íntima em homenagem ao violinista Miguel Livchitz". ${ }^{24}$ Sobre o evento, na coluna Noticiário Elegante, presente na Revista da Semana, foi publicada uma carta de Maria Eugenia para Carnet, relatando a importância do músico russo: 
Miguel Livchitz estreou quinta feira passada no Teatro Municipal. Discípulo do professor Auer, Livchitz alcançou no Conservatório de Petrogrado o primeiro prêmio e o título "virtuose" tornando-se mais tarde a primeira figura da orquestra do conde Chenetieff; viajou; viu a Suécia, a Finlândia, a Romênia, a Bulgária, onde a sua técnica maravilhosa e a sua grande expressão deixaram em todos os espíritos uma impressão de energia e beleza. No Rio, coube ao casal Filinto de Almeida as primícias da audição do Carnaval Russo. E, como todas as pessoas que lá foram, eu aplaudi com muita alma, muito entusiasmo, esse extraordinário violinista. ${ }^{25}$

A ária denominada Carnaval Russo, ao que tudo indica, fazia parte do programa de apresentação de Livchitz e era muito aguardado pelos espectadores. ${ }^{26}$ As reuniões no "salão verde" também ficaram na memória da intelectualidade, uma vez que João Luso, no ano de 1932, afirmou ao relembrar dos encontros:

Releio agora $A$ Casa Verde, Deus sabe com que emoção [...] Os lugares descritos nestas páginas lembram-me com ar de poesia que o tempo vai formando [...]

Tive continuamente, além da sensação de beleza que o livro a toda gente deve produzir, a impressão pessoal, bem íntima e bem egoísta, de ouvir os próprios narradores na sua, na "nossa" sala de Santa Tereza, revelando as inteligências e as vozes no desenvolvimento da obra comum. Era D. Júlia com a fidalguia carinhosa de seu coração, a índole tão generosa que sem deixar de dar aos filhos o máximo de ternura vigilante [...] Depois falava Filinto, com a sua autoridade de erudito, a sua clarividência de observador, o seu amplo descortino de comendador e, sobretudo, a sua exaltação de poeta: [...].

$\mathrm{O}$ ambiente era ao mesmo tempo patriarcal e artístico. As estantes, o piano, quadros e estatuetas, a vasta mesa de trabalho formava um cenário em que o lar e o atelier se conjugavam fraternalmente.

[...] A Casa Verde reconstituiu ontem para a minha emotividade esses aspectos e esta atmosfera [...] por longos anos nos reunimos, em tardes de domingos que tão ditosamente nos compensavam das fadigas e das ansiedades da semana inteira [...]. ${ }^{27}$

\section{A Casa Verde: o romance}

Embora se saiba que o romance $A$ Casa Verde foi produzido inicialmente em folhetim, no final do século XIX, optou-se neste estudo por analisar o 
exemplar impresso pela Companhia Editora Nacional, que, segundo Eliana de Freitas Dutra, foi "responsável pela introdução de novas práticas, inovações e estratégias no campo da edição brasileira durante aqueles anos" ${ }^{28}$ A empresa teve origem em 25 de setembro de 1925, quando Octales Marcondes e José Bento Monteiro Lobato inscreveram na Junta Comercial de São Paulo a nova firma. ${ }^{29}$

Convém notar que o novo empreendimento dos sócios, para além das inovações técnicas, só obteve êxito pela cooperação de Octalles que, mesmo após o colapso da antiga editora de Lobato, quando na ocasião também era sócio da companhia, decidiu esquecer o fracasso anterior e idealizar com o escritor outro projeto:

\footnotetext{
Em lugar de manifestar justificado ressentimento pelo modo com que Lobato mergulhara de cabeça na falência, com a consequente perda de 5000 contos, e praticamente sem seu conhecimento, Octalles começou calmamente a planejar como poderiam continuar trabalhando juntos. Aproximadamente dois meses antes que a antiga companhia fosse finalmente liquidada, ele já persuadira o irrequieto Lobato a construir uma nova editora: os dois eram também sócios numa pequena casa lotérica, cuja venda proporcionou exatamente os cem contos de réis com que agora iriam começar tudo de novo. ${ }^{30}$
}

O romance $A$ Casa Verde foi, pois, publicado nos moldes daquilo que melhor se dispunha no mercado editorial, uma vez que a empresa de Lobato possuía maquinário diferenciado, como o monotipo, o primeiro do Brasil, e inúmeros linotipos e prelos. A partir de uma série de inovações técnicas e com um parque gráfico em ascensão, a editora se lançou em novos métodos comerciais que incluíam a venda de livros em açougues, lojas de ferramentas, bazares, farmácias, bancas de jornal, papelarias da capital e do interior. ${ }^{31}$ Somado todo esse aparato, a Companhia Editora Nacional ainda empregou uma fórmula editorial de significativo sucesso das empresas francesas: as coleções.

Ainda nesse campo técnico-editorial, cumpre lembrar, de acordo com Tania de Luca, que as máquinas velozes que produziam esse material não eram as mesmas utilizadas pela militância operária, fator que traz à luz outro aspecto dessas produções: a função social desses impressos, isto é, tendo em vista a otimização e atualização do maquinário, a perspectiva dessas editoras era, cada vez mais, se inserir no circuito capitalista ${ }^{32}$.

No que diz respeito à sua divisão interna, $A$ Casa Verde é composta por trinta e seis capítulos, a saber: A Casa Verde, A figueira brava, A figueira brava $^{33}$, O juramento, $\mathrm{O}$ incêndio da fábrica, Guilherme Boston, A casa do médico, Primeiro amor, Uma visita, O acidente, Laurinda, A Irmã Pompília, A carta anônima, A espera, A sombra, O pai e a filha, A mãe e o filho, O 
embarque, Luís Ulka, Caridade, Os calons, Sementeira do Futuro, Uma Noite de Tempestade, Contrastes, O ramo de cravos, Um pedido, Uma resolução, O pedido de casamento, Uma esperança, Confissão e Sacrifício, Uma boa nova, A entrevista, No carro, No hospital, Pela religião e O casamento.

Os capítulos eram assinados com os nomes verdadeiros de Julia e seu marido, enquanto, na edição em folhetins, optou-se pelo pseudônimo "A. Julinto". Brito Broca sugeriu que a proliferação de pseudônimos no período tinha relação com a condição de trabalho de muitos intelectuais que "obrigados a escreverem em várias folhas ao mesmo tempo - já que só assim poderiam reunir um ordenado razoável - tinham [...] de mascarar a personalidade a fim de evitar os possíveis inconvenientes dessa atuação simultânea". ${ }^{34}$

No caso de $A$ Casa Verde, para além dessa discussão, supõe-se que o pseudônimo alusivo ao casal tinha a intenção de transparecer o trabalho conjunto dos cônjuges, sem valorar um e preterir o outro. Supõe-se que a junção da letra "A" com partes dos nomes de ambos pretendia dar a ideia de que, apesar da dupla autoria, o mérito deveria ser dado à unidade formada pelos dois.

Figura 2 - Primeiro capítulo do romance $A$ Casa Verde, publicado em folhetins pelo Jornal do Commercio do Rio de Janeiro, em 18 de dezembro de 1899 (Hemeroteca da Biblioteca Nacional)

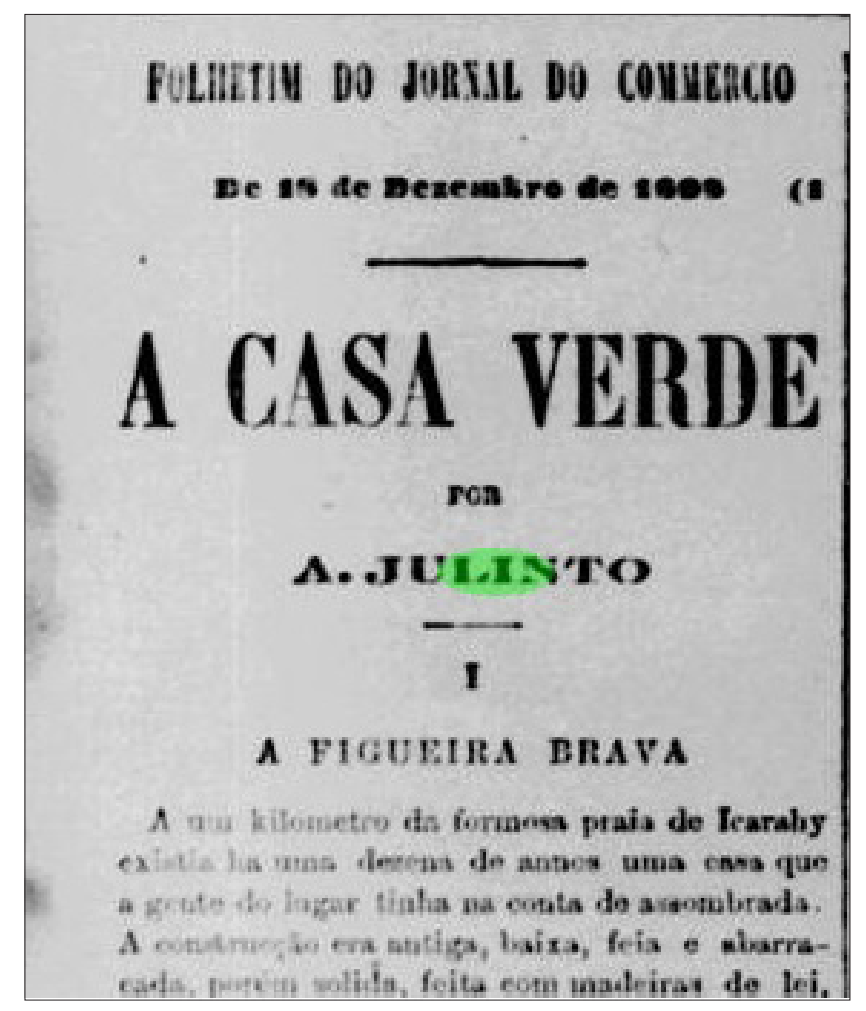


Apesar de a crítica eleger o romance A Falência $(1901)^{35}$ como a obra máxima da autora, e mesmo o livro $A$ viúva Simões (1897) ser comparado à altura de $O$ primo Basílio (1878), de Eça de Queirós, e Madame Bovary (1857), de Gustave Flaubert ${ }^{36}$, Júlia Lopes escolheu A Casa Verde como seu predileto na entrevista concedida pelo casal a João do Rio ${ }^{37}$ no começo do século XX. No diálogo estabelecido com o cronista fica explícita a admiração que os cônjuges tinham um pelo outro, o que é exposto no diálogo a seguir:

- Ainda uma pergunta: dos seus livros qual prefere?

- Vai ficar admirado.

- É A Falência?

- Não.

- O primeiro?

- Não, é $A$ Casa Verde, porque foi escrito de colaboração com meu marido. A Casa Verde lembra-me uma porção de momentos felizes...

Filinto de Almeida, na mesma entrevista, igualmente se isentou da glória e, ao ser questionado sobre a possibilidade de Júlia Lopes de Almeida estar na Academia Brasileira de Letras, reconheceu que na realidade era sua esposa que deveria ter sido escolhida em seu lugar:

- Há muita gente que considera D. Júlia o primeiro romancista brasileiro. Filinto tem um movimento de alegria. - Pois não é? Nunca disse isso a ninguém, mas há muito que o penso. Não era eu que deveria estar na Academia, era ela ${ }^{39}$.

Até mesmo o entrevistador João Rio percebeu que ambos formavam um casal cuja cumplicidade e admiração eram fundamentais para o desenvolvimento de seus trabalhos:

Esse sentimento de mútua admiração é um dos encantos daquele lar. Filinto esquece seus versos e pensa nos romances da esposa. Leva-a a certos trechos da cidade para observar o meio onde se desenvolverão as cenas futuras, é o seu primeiro leitor, ajuda-a com respeito forte e másculo. D. Júlia ama os versos do esposo, quer que ele continue a escrever, coordena o volume prestes a entrar no prelo. E ambos, nessa serena amizade, feita de amor e de respeito, envolvem os filhos numa suave atmosfera de bondade. ${ }^{40}$

A intenção de fazer o leitor acreditar que $A$ Casa Verde havia sido composta por uma unidade autoral fica evidente quando o Jornal do Commercio, em sua seção Gazetilha, informou que: "Encetamos hoje a publicação de um 
novo romance, A Casa Verde, de festejada pena brasileira. $\mathrm{O}$ folhetim tem muitos incidentes, muito movimento e, cremos nós, não deixará de agradar aos nossos leitores". ${ }^{41}$ A expressão "festejada pena brasileira" não traria, de maneira clara, a quantidade, o gênero e a identificação dos possíveis autores, o que, segundo Roger Chartier, garantiria a possibilidade de que o conteúdo da obra fosse mais do que o nome dos autores. ${ }^{42}$

Quanto ao enredo da história, tem-se como protagonista a jovem Mary Lane, filha do inglês Mr. Henrique Lane, dono de uma fábrica, cuja residência da família era conhecida como "casa verde". Mr. Lane era um industrial viúvo que fora casado com uma brasileira. Seu principal objetivo no Brasil era fazer fortuna com seu empreendimento industrial e cuidar de sua filha até o casamento dela, tendo em vista o fato de a esposa já ter falecido e, desse modo, não haver ninguém para orientar a menina a respeito disso.

A filha do industrial, Mary Lane, era uma jovem mulher da elite carioca que possuía uma criada, Rita, e uma preceptora, que se chamava Madame Girard. Na trama, Mary Lane foi descrita como:

Filha de baiana, o seu tipo compartilhava das duas raças, inglesa e brasileira. Se os cabelos eram negros, a pele era alva, e os olhos de um azul escuro, por vezes límpido, por vezes sombrio. A originalidade de seu tipo e seu modo aparentemente frio e concentrado faziam-na parecer antipática as pessoas vulgares; mas as que dela se aproximassem, ou mesmo de longe observassem com atenção a doçura do sorriso e a harmonia do gesto, sentiamse logo vencidas pela sua finura e o seu encanto. ${ }^{43}$

A história se inicia quando a protagonista, após praticar o treino de tiro com sua preceptora, feriu gravemente um cigano. O homem, escondido no alto da figueira, tentava examinar o número de cavalos de raça que a "casa verde" possuía. Ao perceber que o atingiu gravemente, Mary, com ajuda de Madame Girard, escondeu o cigano em seu quarto e lhe prestou os primeiros socorros. Além delas, o doutor Eduardo Abrantes foi chamado para ver o enfermo. No entanto, ficou combinado que o médico não poderia comunicar o fato a ninguém, muito menos ao dono da casa.

Sem desconfiar que houvesse em sua residência um cigano alvejado por sua própria filha, Mr. Lane tentava reconstruir sua fábrica após um incêndio ocasionado por uma operária anarquista, Teresa Nutti. Às escondidas, horas após o incidente, a mulher surpreendeu o proprietário:

Quem é você? - perguntou Mr. Lane, segurando-a pelo pulso ossudo e forte, com violento desespero.

Sou a miséria! Sou a fome! Sou a inimiga dos ricos! Sou o 
protesto da vossa felicidade, eis o que sou! Odeio todos os que vivem bem, todos os que tem dinheiro e exploram os que não tem!... Percebes agora, velho feliz, nababo glorioso? Sou rico à custa do meu trabalho - respondeu Mr. Lane, maquinalmente, sem largar os pulsos da megera.

$\mathrm{Ah}$ ! Ah! Pensas que eu também não trabalhei, eu?! Sou da Europa como tu; tu és da Inglaterra poderosa, senhora do mundo; eu sou da velha Itália, nação dos pobres... Lá trabalhei desde menina; corria-me o sangue das unhas à força de lidar... . ${ }^{4}$

A discussão acalorada entre os personagens evidencia os conflitos reais entre imigrantes operários e os patrões, nos anos finais do século XIX e início do XX. Como observou Angelo Trento, por volta de 1900, a migração para alguns estados brasileiros cessou, contudo, a cidade do Rio de Janeiro continuou a atrair italianos vindos de outras partes do Brasil, embora num ritmo inferior em relação ao passado. Desse modo, o número de residentes foi aumentando até 1910, para, em seguida, decrescer: de 20.000, em 1895, passou para 30.000, em 1901, e em seguida, 35.000 (1910), 31.929 (1920) e 22.768 (1940). ${ }^{45}$

Outro personagem importante na trama é Guilherme Boston, o guarda livros da fábrica de Mr. Lane. Ao se apaixonar pela filha do patrão, fez de tudo para casar-se com a jovem:

Era um rapaz de estatura mediana, de rosto oval, claro e rosado, com olhos garços e cabelos loiros, raros e finos, principalmente penteados; sobre os lábios muito vermelhos arqueava-se lhes o bigode pequeno, também loiro. A parte a cor dos cabelos, que denunciava a origem estrangeira, tudo nele era vulgar, nem feio nem belo, sem nenhum traço saliente, sem nenhuma curva característica, sem nenhum defeito que interrompesse a monotonia das feições e lhe marcasse um ar próprio, individual, distinto da massa comum e anônima de sua classe. ${ }^{46}$

Se, por um lado, Guilherme Boston, inescrupulosamente, esforçava-se para conquistar o coração de Mary Lane, de outro, uma tensão amorosa entre Mary e o doutor Abrantes passou a se desenvolver no enredo. Todavia, Boston dissimulava seu comportamento e conseguia enganar a todos, tentando passar uma imagem de "bom moço".

Moralmente, todos o achavam um "bom rapaz", porque era serviçal e insinuante, e a sua voz, pausada e doce, saia-lhe sempre em frases de bom senso, bem ordenadas, indulgentes para as faltas alheias e sempre elogiosas para os patrões e gerentes das casas em que estivera empregado ${ }^{47}$. 
O antagonista da história, portanto, se concentrava na figura de Guilherme Boston, disposto a fazer o que fosse preciso para casar-se com Mary Lane e herdar toda a herança de sua família. Enquanto isso, o Dr. Eduardo Abrantes tentava lutar contra o sofrimento que o amor que tinha pela jovem lhe causava, a ponto de atrapalhar sua atividade profissional:

Havia curtos dias que a vira pela primeira vez, e já não pensava em mais ninguém. Aquele conhecimento, feito em condições extraordinárias e dramáticas, punha-o desde o seu início na intimidade da pessoa mais linda e perturbadora que tinha visto em toda a sua vida. ${ }^{48}$

O fato era que, além de bonita, educada e culta, Mary Lane era uma mulher independente, tendo em vista as condições reais de existência destinadas à mulher no final do século XIX. Pode-se inferir que a construção do personagem de Mary Lane foi inspirada na própria história de vida de Júlia Lopes de Almeida. A escritora foi educada para desenvolver todas as virtudes que uma mulher de família burguesa oitocentista poderia apresentar: lia, escrevia e tocava piano. Já no campo ficcional, em uma conversa entre pai e filha, Mary Lane desafiou:

\begin{abstract}
Absolutamente! Vivo a meu gosto; nado, remo, governo o meu carro, galopo no meu cavalo, leio os meus romances... toco em excelente piano o meu querido Mendelssohn... acha pouco? ${ }^{49}$
\end{abstract}

Ainda no campo da cultura, são várias as referências, na obra $A$ Casa Verde, à Inglaterra, como exemplo de civilidade, ou à lembrança de escritores ingleses, autores provavelmente bastante estimados pelo casal. Mary Lane, nas horas de descanso, por exemplo, lia uma ou outra obra de autores da Inglaterra, como enfatiza certos trechos do texto: "Na sua rede de seda, Mary, deixando pender na mão o seu volume de Thackeray". ${ }^{50}$ Cabe lembrar que tal escritor foi um romancista de sucesso na era Vitoriana, autor de obras renomadas como Feira das Vaidades (1847-1848). Em anúncio de 30 de agosto de 1872, o Correio Paulistano apresentou um catálogo de escritores europeus cujos livros estavam à venda:

\title{
ENGLISH BOOKS by
}

Dickens, Bulwer, Scott, Disraeli, W. Collins, Lever, Thackeray, Trollope and other select authors; also, translations from some of the best French authors, such as; George Sand, E. Sue, Dumas, Aimard and others; Chiefly. TAUCHNITZ EDITION. A large stock and fresh supplies, received monthly. George G. Harvey ${ }^{51}$ (grifo nosso). 
É importante reforçar, o uso constante de elementos anglófilos na trama de $A$ Casa Verde. Em muitos momentos, os personagens referem-se à residência como Green House, como se quisessem, de alguma maneira, idealizar uma experiência na Inglaterra. A comunicação familiar em Green House, ou melhor, os gracejos entre pai e filha eram na língua materna de Mr. Lane: "My dear Mary", "My little darling" 52 . Nesse sentido, o trabalho de May Bletz parece revelador nesse campo. Ao direcionar seus estudos para a anglofilia em $A$ Casa Verde, Bletz afirma em seu artigo: "England is an example worthy to be imitated, however, as I will show, it is only through the biracial daughter that this potential can be fully realized". ${ }^{53}$ Ao ampliar a discussão, afirma a autora que Mary Lane seria peça chave nesse projeto, visto que, sua descendência, de pai inglês e mãe baiana, seria a metamorfose pragmática do imaginário da cultura europeia. A protagonista tinha hábitos e maneiras refinados como os europeus e também possuía as virtudes de simplicidade e coragem do povo brasileiro. O pesquisador Jeffrey Needell argumenta que, "para os brasileiros do século XIX, a civilização era a França e a Inglaterra. Na verdade, desde a época colonial, os brasileiros seguiam o exemplo português e procuravam nos dois países o que houvesse de melhor". ${ }^{54}$

No decorrer da narrativa, após recuperar-se da enfermidade, o cigano ferido por Mary Lane no começo da trama, Luis Ulka, fugiu e retornou a sua comunidade. Com medo de novas investidas, Mr. Lane reforçou a vigilância na "casa verde", entretanto, diferentemente do que ocorria na Inglaterra, não se sentia realmente seguro: “[...]... não estava tranquilo, vinha-lhe uma espécie de raiva daquele lugar e aquela polícia! Ah! Se aquelas coisas tivessem passado na sua Inglaterra! Aqui os indivíduos escapavam-se-lhe dos olhos, como se fossem líquidos". ${ }^{55}$

Quanto à sua filha, ao zelar por sua segurança, Mr. Lane resolveu enviá-la para a casa de seus avós maternos na Bahia, medida que inquietava o Dr. Abrantes:

Depois de ter entrado assim na vida de Mary poderia ainda temer não a alcançar um dia como mulher? Esposa! Ah!... ao mesmo tempo que essas ideias loucas esvoaçavam pelo espírito, nascia-lhe do fundo do coração, germinando de ciúme, uma suspeita cruel. E se ela não fosse pura? ${ }^{56}$

Diante da questão, não se pode esquecer, também da longa simbologia da virgindade feminina. Yvonne Knibiehler esclarece com lucidez que, durante os séculos cristãos, um bom número de mulheres preservou sua pureza como forma de liberdade e fonte de poder, exprimindo com tal atitude sua parcela de autonomia e iniciativa. ${ }^{57}$ Por outro lado, na ótica masculina, a virgindade era preciosa aos olhos dos homens, porque assegurava a supremacia masculina: era o esposo que deflorava sua esposa e a transformava em mulher e em mãe. ${ }^{58}$ 
Desse modo, a imagem da mulher para os autores de $A$ Casa Verde apresenta-se essencialmente conservadora. Apesar de as moças da elite terem certa independência e praticarem as atividades como leitura, passeios a cavalo, bordarem e tocarem piano, suas atitudes não chegavam a desabonar o imaginário masculino. Por outro lado, a mulher das classes mais baixas sofria com as intempéries de seus maridos. A personagem Guilherme Boston, por exemplo, após lutar para conseguir o amor de Laurinda, sua então pretendente, convencera-a a fugir de casa e, com isso, afirmam os autores: "Guilherme vencera; Laurinda, apaixonada, só tinha uma aspiração: ser mulher daquele belo rapaz". ${ }^{59}$ No entanto, o casal não conseguiu se unir pelos laços do matrimônio, por falta de dinheiro, e passou a morar informalmente em um casebre. Além disso, o amor de Guilherme Boston arrefeceu e suas dívidas aumentaram. Mesmo assim, Laurinda "vivia alimentando a esperança de saldar a dívida de Guilherme e no mesmo dia casar-se". ${ }^{60}$

Após meses da ausência de Mary Lane em Niterói, o Dr. Abrantes não tinha mais esperanças de casar-se com ela. A sua tristeza era tamanha que sua mãe arranjou um casamento às pressas com Tilde, a filha de um floricultor, que desde sempre era apaixonada pelo médico. No entanto, não havia reciprocidade nesse sentimento. Por seu turno, Mary Lane, declaradamente com ciúmes pelo noivado de Dr. Abrantes, relutava em aceitar a possibilidade de se casar com Guilherme Boston. Em uma discussão entre Mr. Lane e sua filha, fica clara a contrariedade da protagonista em ficar ao lado do guarda-livros:

- Agora dize-me: pensaste no que eu te disse?

- No casamento com Guilherme Boston?

- Sim.

- Pensei.

- E então?

- Resolvi ir com o senhor para a Nova Zelândia.

- És teimosa, já te disse que isso é impossível.

- Por quê?!

- Por que não quero.

- É a razão mais forte...

- Ou tu te casas ou...

- Vou para um convento?

- Ou eu não faço a viagem e perco interesses enormes... enormíssimos!

- Isso para um inglês é um sacrifício horroroso...

- É.

- Casar-se sem amor é ainda maior.

- Qual!

- É.

- Amor! Amor! Ora, basta que o homem ame. A mulher nasceu para ídolo e não para idolatria. ${ }^{61}$ 
O propósito de se casar sem amor não agradava Mary Lane, tanto que interpelou seu pai, ironicamente, sobre essa possibilidade. Afinal, a ideia de seu pai tornara-se fixa: ou casava ou a levaria a um convento. A chantagem apresentada pelo seu pai vai ao encontro da preocupação com a tutela das mulheres à época. Leila Mezan Algranti afirma que "a ausência de uma tutelagem masculina ameaçou durante muito tempo as mulheres sós das camadas intermediárias e mais altas da sociedade, que viviam dos rendimentos de seus esposos e pais". ${ }^{62}$

Com certeza, a ideia de se enclausurar em um convento não passava pela cabeça de Mary Lane, mas um acontecimento inesperado na história reorganizaria o destino dos personagens. Guilherme Boston foi desmascarado pela sua ex-mulher, que vivia na miséria à espera da ajuda financeira de Boston. Laurinda encontrou Mr. Lane e explicou toda a história de vida do companheiro, relatando suas mentiras e falcatruas. A atitude fez que Henrique Lane desistisse da ideia de casar sua única filha com um tipo dessa espécie e sugeriu que Boston e Laurinda se unissem finalmente de maneira formal. No entanto, após a volta de ambos da "casa verde", Boston, furioso com o comportamento de Laurinda e disposto a não desistir de seus planos de enriquecimento, sufocou sua parceira até a morte:

Desesperado, Guilherme Boston lançou as mãos ao pescoço da filha do Major Figueiredo. A moça estendeu os braços, querendo repeli-lo, mas Guilherme tinha os pulsos fortes, e na cegueira da raiva comprimiu mais e mais a garganta de Laurinda, cujos olhos esbugalhados luziam na sombra. Houve um rubor de um corpo que se debatia, de uns dentes que rangiam com ódio, de uma respiração arfante... Mas tudo isso foi abafado pela bulha do carro, entrado agora nas ruas da cidade, deslizando sobre as pedras das calçadas. $\mathrm{O}$ ato foi rápido. Quando Guilherme retirou as mãos, Laurinda estava morta. ${ }^{63}$

Com a desmoralização de Guilherme Boston e sua consequente fuga da polícia, o contato de Mary Lane e Doutor Abrantes se tornou cada dia mais intenso, abrindo desse modo a possibilidade de se casarem. Os preparativos para a cerimônia foram realizados, mas Mary Lane ainda precisava saber se Tilde aceitaria a união de Mary com o médico. A filha do floricultor, diante do infortúnio de ver seu amado prestes a contrair núpcias com outra que não ela, resolveu se dedicar à vida religiosa. Nesse caso, a clausura representava a única saída para Tilde. Em outras palavras, a sua condição pobre a excluía de uma possível disputa em relação à Mary e, sobretudo, visava "preservar a honra e controlar a sexualidade feminina". ${ }^{64}$

No entanto, no fim do romance, após a solenidade de matrimônio, Tilde demonstrou que a disputa pelo médico era coisa do passado e o doutor não mais 
lhe interessava: "A cerimônia terminou e as primeiras folhas que caíram sobre o véu de Mary foram as atiradas pelas mãos generosas de Tilde. As duas moças abraçaram-se e enquanto Mary dizia à outra - obrigada - Tilde murmurava com sinceridade: Seja feliz" ${ }^{65}$.

O romance A Casa Verde, portanto, narra a história de vida de uma jovem da elite, que possuía certa independência, tanto que não foi obrigada a casar-se com quem não queria, fruto de um arranjo arquitetado pelo pai. Sua intenção era se unir com o homem que amava e, talvez, a trajetória narrada, na visão do casal Almeida, se assemelhasse com aquela vivenciada por Julia Lopes. De fato, embora criada e educada dentro das regras de um lar da elite do Rio de Janeiro, Julia Lopes pôde ter uma carreira literária e se casar com o pretendente escolhido por ela mesma, sem a interferência do pai ou da família, ainda que o progenitor de Julia Lopes de Almeida tenha imposto a Filinto de Almeida sua ida para Portugal.

O romance também traz um ponto importante sobre a vida cultural do Rio de Janeiro: a ideia da europeização, presente já de início nos nomes dos personagens, como no caso de Guilherme Boston e Mary Lane, antagonista e protagonista da história. O cenário da trama, o Rio de Janeiro da belle époque, mostra o momento cultural caracterizado por transformações nos modos de pensar e viver o cotidiano, a partir da idealização de uma vivência francesa ou inglesa. Em A Casa Verde, especificamente, o olhar direcionou-se para a Inglaterra, terra do personagem de Mr. Lane.

Outro fato que confere o clímax central à trama é a morte brutal da personagem Laurinda. Vítima do abandono do marido e de sua fúria, a jovem foi assassinada de maneira bestial. Apesar de o termo "feminicídio" ser uma referência da contemporaneidade, o leitor de A Casa Verde percebe que este é um fato corriqueiro que assombra as mulheres do Brasil há séculos.

\section{Notas}

1 FERREIRA, Antônio Celso. A fonte fecunda. IN: PINSKY, Carla Bassanezi; LUCA, Tania Regina de. O Historiador e suas Fontes. São Paulo: Contexto, 2009. p. 75.

2 FERREIRA, Antônio Celso. Op.cit. p. 80.

3 Guarda-livros era o nome dado aos contadores e profissionais contábeis no Brasil desde os primórdios do século XX, momento em que houve a inauguração da Escola de Comércio Álvares Penteado, em São Paulo, em 1902. Ver http://www.fecap.br/novosite/institucional/ index.php. Acesso em 10 de fev. de 2017.

4 ALMEIDA, Filinto; ALMEIDA, Julia Lopes. A Casa Verde. São Paulo: Companhia Editora Nacional. 1932.p. 97.

5 SEVCENKO, Nicolau. Literatura como missão: tensões sociais e criação cultural na Primeira República. São Paulo: Companhia das Letras, 2003. p.29. 
6 LUCA, Tania Regina de. História dos, nos e por meio dos periódicos. IN: PINSKY, Carla B. Fontes Históricas. São Paulo: Contexto, 2011.p. 132.

7 Ver BRASIL, Constituição (1891). Constituição da República Federativa do Brasil. Disponível em: http://www.planalto.gov.br/ccivil_03/Constituicao/Constituicao91.html. Acesso em 01 de mar. de 2017.

8 Ver Biografia de Filinto de Almeida: http://www.academia.org.br/academicos/filinto-de-almeida/biografia. Acesso em 01 de mar. de 2017.

9 Ver capítulo intitulado "Um lar de artistas". RIO, João do. O momento literário. Rio de Janeiro: Fundação Biblioteca Nacional/Dep. Nacional do Livro, 1994.

10 Carlos Augusto Ferreira (1846-1913), gaúcho, foi colaborador do Correio Paulistano e redator-chefe, diretor e depois proprietário do jornal Gazeta de Campinas. Morou na cidade de Amparo, interior de São Paulo, abriu um colégio só para meninos, que servia como internato e externato. Também foi, possivelmente, o primeiro tradutor de Baudelaire no Brasil e ficou conhecido também como ex-noivo de sua conterrânea Amália dos Passos Figueiroa (1846-1875), integrante da família de mulheres literatas e editoras da revista Corimbo. VER ELEUTÉRIO, Maria de Lourdes. VIDAS DE ROMANCE: As mulheres e o exercício de ler e escrever no entresséculos 1890-1930. Rio de Janeiro: TOPBOOKS, 2005. p.78.

11 A entrevista foi realizada na casa do neto de Júlia Lopes de Almeida, Dr. Claudio Lopes de Almeida, em 11 de janeiro de 2016. ALMEIDA, Claudio Lopes de. Júlia Lopes de Almeida. [jan. 2016]. Entrevistador: Deivid Aparecido Costruba. Rio de Janeiro, janeiro de 2016.

12 As informações biográficas sobre a escritora foram encontradas em: MOREIRA, Nadilza M. B. A condição feminina em Júlia Lopes de Almeida e Kate Chopin. Tese (Doutorado em Letras). São José do Rio Preto: Universidade Estadual Paulista/IBILCE, 1998.

A condição feminina revisitada: Júlia Lopes de Almeida e Kate Chopin. João Pessoa: Editora universitária / UFPR, 2003; DE LUCA, Leonora. O feminismo possível de Júlia Lopes de Almeida (1862-1934). Cadernos Pagu. Campinas, v.12, p. 275-299, 1999; . Amazonas do pensamento: a gênese de uma intelectualidade feminina no Brasil. 2004. Tese (Doutorado em Ciências Sociais). IFCH, UNICAMP, Campinas, 2004; ELEUTÉRIO, Op.cit.; COSTRUBA, Deivid Aparecido. CONSELHO ÀS MINHAS AMIGAS: os manuais de ciências domésticas de Júlia Lopes de Almeida (1896-1906). Dissertação (Mestrado em História). Universidade Estadual Paulista, Assis, 2011 e JÚLIA Lopes de Almeida. In: ENCICLOPÉDIA Itaú Cultural de Arte e Cultura Brasileiras. São Paulo: Itaú Cultural, 2017. Disponível em: $<$ http://enciclopedia.itaucultural.org.br/pessoa443758/julia-lopes-de-almeida>. Acesso em 03 de mar. de 2017. Verbete da Enciclopédia.

13 O Estado de S. Paulo, 11/11/1896. p. 01.

14 ELEUTÉRIO, Maria de Lourdes. Op.cit. p. 76.

15 Segundo Michele Asmar Fanini, os nomes sugeridos por Lúcio de Mendonça foram: Adolfo Caminha, Afonso Celso, Alberto de Oliveira, Alberto Silva, Alcindo Guanabara, Araripe Junior, Artur Azevedo, B. Lopes, Capistrano de Abreu, Carlos de Laet, Coelho Neto, Constâncio Alves, Eduardo Salamonde, Escragnolle Dória, Taunay, Eunápio Deiró, Ferreira de Araújo, Graça Aranha, Guimarães Passos, Inglês de Sousa, Joaquim Nabuco, José Veríssimo, Júlia Lopes de Almeida, Luís Delfino, Luís Murat, Machado de Assis, Medeiros e Albuquerque, Olavo Bilac, Osório Duque-Estrada, Pedro Rabelo, Ramiz Galvão, Rodrigo Octávio, Rui Barbosa, Silva Ramos, Teixeira de Melo, Urbano Duarte, Valentim Magalhães, Virgílio Várzea e Xavier da Silveira. Destacam-se aqui em negrito os escritores que integraram posteriormente a ABL. Percebe-se que Filinto de Almeida não apa- 
rece na relação primária de Mendonça, no entanto, Júlia Lopes de Almeida é a única mulher desta primeira lista. Ver nota de rodapé 174 de FANINI, Michele Asmar. Fardos e fardões: Mulheres na Academia Brasileira de Letras (1897-2003). 2009. Tese (Doutorado em Sociologia). FFLCH, USP, São Paulo, 2009. p. 155.

16 VENÂNCIO FILHO, Alberto. As mulheres na Academia. Revista Brasileira. out./nov./ dez. 2006, ano XIII, n.49, p. 8-9.

17 As três Júlias a que Mendonça faz referência no título do seu texto referem-se a Júlia Lopes, Júlia Cortines (1868-1948) e Francisca Júlia (1871-1920).

18 MENDONÇA, Lúcio. As três Júlias. Almanaque Brazileiro Garnier. 1907. p.249.

19 Apud MACHADO NETO, Antonio Luís. Estrutura social da república das letras: sociologia da vida intelectual brasileira, 1870-1930. São Paulo, Grijalbo: Ed. da Universidade de São Paulo, 1973. p.193.

20 BOURDIEU, Pierre. A dominação masculina. Rio de Janeiro: BestBolso, 2014. p.11-12.

21 Cumpre lembrar que, de acordo com o artigo 12 da Constituição de 1891, são considerados "cidadãos brasileiros ou estrangeiros que, achando no Brasil aos 15 de novembro de 1889, não declararem, dentro de seis meses depois de entrar em vigor a Constituição, o ânimo de conservar a nacionalidade de origem". Desta forma, o referido artigo assegurou a naturalização automática de Filinto de Almeida.Ver BRASIL, Constituição da República Federativa do Brasil. Disponível em: http://www.planalto.gov.br/ccivil 03/Constituicao/ Constituicao91.htm. Acesso em: 09 de fev. 2017.Ver também FANINI, Michele Asmar. Julia Lopes de Almeida: entre o salão literário e a antessala da Academia Brasileira de Letras. Estudos de Sociologia (São Paulo), v.14, p. 317-338, 2009.p.331.

22 O imparcial, 17/12/1917. p. 06.

23 O imparcial, 25/12/1917. p. 08.

24 O imparcial, 06/06/1921. p. 04.

25 Revista da Semana, 11/06/1921. p. 26.

26 O Paiz, 06/06/1921. p. 05.

27 Jornal do Comercio, 03/07/1932. p. 02

28 DUTRA, Eliana de Freitas. Companhia Editora nacional: tradição editorial e cultura nacional no Brasil dos anos 30. In: I Seminário sobre o Livro e a História Editorial, 2004, Rio de Janeiro, 2004. p. 01.

29 Segundo um dos biógrafos de Monteiro Lobato, a ideia do escritor era inundar o país de livros e, para isso, não mediu esforços para fazê-lo. Algumas medidas foram implementadas como a readequação dos livros didáticos, além da introdução de novas técnicas de produção e divulgação das obras. Desse modo, "o escritor brasileiro encontrou [um] editor que se aventurava a tiragens de 20 a 30 mil exemplares. [...] E ao lado dos originais brasileiros, o mercado de traduções, até então praticamente nulo, ganhou impulsos insuspeitados. Os métodos comerciais eram os mais modernos - e a experiência com a venda de livros a prestações foram iniciadas" Apud DUTRA, Op.cit. p. 02-03.

30 HALLEWELL, Laurence. O livro no Brasil: sua história. São Paulo: T. A. Queiroz: Ed. da Universidade de São Paulo, 1985.p.267-268.

31 DUTRA, Op.cit. p. 05.

32 LUCA, Tania Regina de. Op. cit. p.132-133. 
33 No livro A Casa Verde, o segundo e o terceiro capítulo possuem o mesmo nome.

34 BROCA, Brito. O anonimato e o pseudônimo na Literatura Brasileira. IN: . Horas de leitura. Rio de Janeiro: MEC-INL, 1957, p.107.

35 Certa vez afirmou José Veríssimo, um dos membros e fundador da cadeira $n^{\circ} 18$ da ABL, que "com seu livro A Falência, a sra. Júlia Lopes de Almeida toma decididamente o lugar (...) entre os nossos romancistas" Ver VERÍSSIMO, José. Estudos de literatura brasileira. Rio de Janeiro: H. Garnier, 1910.p.141.

36 Os estudos literários acerca da obra de Júlia Lopes de Almeida direcionam-se nesta perspectiva. Para Romair Alves de Oliveira, "grande parte das personagens criadas por Júlia Lopes de Almeida lembra, em sua composição, a complexidade romântica de Ema Bovary, na obra Madame Bovary (1857), e Luiza do romance português O Primo Basílio (1878), respectivamente de G. Flaubert e Eça de Queiroz. Tais personagens, com perfis românticos, protagonizam obras realistas ao mesmo tempo em que se dá o inverso, isto é, personagens com características realistas protagonizando obras românticas”. Ver OLIVEIRA, Romair Alves de. A escritura de resistência em Júlia Lopes de Almeida, A Viúva Simões. Tese (Doutorado em Letras). Universidade Federal da Paraíba, João Pessoa, 2008. p. 102.

37 Cabe lembrar que o inquérito teria sido inspirado naquele realizado anos antes por Jules Huret, que publicara em L'Echo de Paris, no ano de 1891, um questionário explorando a situação do naturalismo francês. As entrevistas foram reunidas no compêndio Enquete sur l'Evolution Littéraire. João do Rio, deste modo, resolveu, à brasileira, entender o perfil da nata literária nacional na primeira década do século XX. Ver RIO, João do. Op. cit.

38 RIO, João do. Op. cit. p. 37.

39 RIO, João do. Op. cit. p. 33

40 Idem.

41 Jornal do Comercio, 18/12/1898. p.01.

42 CHARTIER, Roger. A ordem dos livros. Leitores, autores e bibliotecas na Europa entre os séculos XIV e XVIII. Brasília: UNB, 1994. p. 85.

43 ALMEIDA, Filinto; ALMEIDA, Julia Lopes. Op.cit. .p. 08-09.

44 Idem. p.34

45 Cabe destacar que eram muitos os ofícios a que se dedicavam os imigrantes italianos no Rio de Janeiro, como os de engraxate, amolador, sapateiro, varredor de ruas, pedreiro, garçom, operário têxtil, alfaiate, barbeiro, marceneiro e jardineiro. Ver capítulo II - 2.2 - Do Rio de Janeiro à Amazônia. TRENTO, Angelo. Do outro lado do Atlântico: Um século de imigração Italiana no Brasil. São Paulo: Livraria Nobel, 1989. p. 103.

46 ALMEIDA, Filinto; ALMEIDA, Julia Lopes. Op.cit. p. 51-52.

47 Idem. p. 52.

48 Idem. p. 64.

49 Idem. p. 67.

50 Idem. p. 83.

51 Correio Paulistano, 30/08/1872. p.01.

52 ALMEIDA, Filinto; ALMEIDA, Julia Lopes. Op.cit. p. 194. 
53 Tradução nossa: “A Inglaterra é um exemplo digno de ser imitado, no entanto, como vou mostrar, é apenas por meio da filha birracial que este potencial pode ser plenamente realizado". Ver An example worth following: Anglofilia in A casa verde by Júlia Lopes de Almeida (Um bom exemplo a ser seguido: Anglofilia em A Casa Verde de Júlia Lopes de Almeida), apresentado no nono Congresso Internacional da Brazilian Studies Association (BRASA) realizado do dia 27 a 29 de março de 2008, na Tulane University em Nova Orleans, Louisiana. Disponível em: http://www.brasa.org/wordpress/Documents/BRASA IX/May-Bletz. pdf. Acesso em 05 de fev. de 2017.

54 NEEDELL, Jeffrey D. Belle époque tropical: sociedade e cultura de elite no Rio de Janeiro na virada do século. São Paulo: Companhia das Letras, 1993.p.49.

55 ALMEIDA, Filinto; ALMEIDA, Julia Lopes. Op.cit. p. 249.

56 Idem. p. 111.

57 KNIBIEHLER, Yvone. História da virgindade. São Paulo: Contexto. 2016.p. 25.

58 Idem.

59 ALMEIDA, Filinto; ALMEIDA, Julia Lopes. Op.cit. p. 111.

60 Idem. p. 115.

61 Idem. p.358.

62 ALGRANTI, Leila Mezan. Honradas e Devotas: Mulheres na Colônia. (Estudo sobre a condição feminina através dos conventos e recolhimentos do sudeste -1750-1822). Tese (Doutorado em História). Universidade de São Paulo, São Paulo, 1992.p.53.

63 ALMEIDA, Filinto; ALMEIDA, Julia Lopes. Op.cit. p. 404.

64 ALGRANTI, Leila Mezan. Op.cit. p. 51.

65 ALMEIDA, Filinto; ALMEIDA, Julia Lopes. Op.cit. p.424.

\author{
Recebido em 16/03/2017 \\ Aprovado em 11/11/2017
}

